\title{
Moral requirements are still not rational requirements
}

\section{Paul NoordhoF}

According to Michael Smith, the Rationalist makes the following conceptual claim.

If it is right for agents to $\phi$ in circumstances $C$, then there is a reason for those agents to $\phi$ in $C$ (Smith 1994: 62).

Smith holds that there is a 'simple, powerful, line of argument in support of [it]' based on the 'truism that we expect agents to do what they are morally required to do' (Smith 1994: 85). Here is the argument that Smith provides.

Moral requirements apply to rational agents as such. But it is a conceptual truth that if agents are morally required to act in a certain way then we expect them to act in that way. Being rational, as such, must therefore suffice to ground our expectation that rational agents will do what they are morally required to do. But how could this be so? It could only be so if we think of the moral requirements that apply to agents as themselves categorical requirements of rationality or reason. For the only thing we can legitimately expect of rational agents as such is that they do what they are rationally required to do (Smith 1994: 85).

Smith seems to use 'agent' and 'rational agent' more or less interchangeably. That suggests either that he takes agency to involve rationality or that 'agent' is just short for 'rational agent'. So I shall use 'agent' hereafter to mean 'rational agent'. The first sentence of the passage seems to presuppose the truth of Rationalism rather than constitute the beginning of an argument for it. So I shall take the argument to proceed from the second sentence, as follows.

(1) If agents are morally required to $\phi$ in circumstances $\mathrm{C}$ (i.e. if it is right for agents to $\phi$ in circumstances $\mathrm{C}$ ), then we legitimately expect them to $\phi$ in $\mathrm{C}$.

(2) We legitimately expect them to $\phi$ in $\mathrm{C}$ if and only if the moral requirement to Do $\phi$ in $C$ is a requirement of reason for all agents.

(3) If the moral requirement to $D o \phi$ in $C$ is a requirement of reason for all agents, then there is a reason for those agents to $\phi$ in $\mathrm{C}$. 
Therefore,

(4) Rationalism: If it is right for agents to $\phi$ in circumstances C, then there is a reason for those agents to $\phi$ in C. ${ }^{1}$

When Smith talks of our legitimate expectation that agents $\phi$ in $C$, he means that we legitimately believe that they will act and not that we legitimately believe that they should act (Smith 1994: 85-86). I shall not seek to deny that premiss (1) is correct so understood although it could be questioned. Premiss (3) seems uncontroversial.

My beef is with premiss (2). The left-right reading of the biconditional asserts that only if moral requirements are requirements of reason, does it follow that our expectations are legitimate. In the first section of this paper, I argue that Smith's attempt to demonstrate this fails. The right-left reading of the biconditional asserts that, in any event, if moral requirements were requirements of reason, then our expectations would be legitimate. In the third section of this paper, I question whether this is correct. I argue that there would be more plausible sources of the legitimacy of our expectations given Smith's understanding of what constitutes a requirement of reason. So even if Smith had established what I say he does not in section 1 , this would be to no avail given the conclusion of section 3 .

\section{Two ways in which the legitimate expectation may be grounded in something other than rationality}

Smith assumes that the rationality of an agent must ground the legitimacy of the expectation that he or she will act as he or she should. But why should an agent's rationality be the basis for the legitimate expectation? Why should it not be the fact that they are moral or have certain entrenched desires? In effect, Smith's answer is that he can show that moral requirements are requirements of reason. So these alternatives are not genuine.

His argument runs like this.

(2a) If $S$ judges that $p, T$ judges that not- $p$, and $p$ purports to concern something objective, then at least one of $\mathrm{S}$ and $\mathrm{T}$ is susceptible to rational criticism

(2b) Moral judgements purport to concern something objective. Therefore,

(2c) It is a requirement of reason that, if $p$ is a moral truth, $S$ judge that $p$.

(2d) If $S$ judges that it is right for him or her to $\phi$ in $C$ and $S$ is practically rational, then $S$ is motivated to do $\phi$ in C (Smith 1994: 61).

${ }^{1}$ Smith offers a second argument based upon what it is to approve and disapprove of something. The considerations offered below undermine it as well (see Smith 1994: 87-91). 
Therefore,

(2e) It is a requirement of reason that, if 'it is right for $S$ to $\phi$ in $C$ ' is a moral truth, $S$ is motivated to do $\phi$ in $C$ (Smith 1994: 86-87).

If an agent, $S$, makes a moral judgement, then $S$ is practically irrational if $S$ isn't motivated to act upon it. If $S$ makes a false moral judgement, then $S$ is subject to rational criticism. So it is a requirement of reason for all agents to find out and then be motivated to act upon moral requirements. The basis of the legitimate expectation lies in the motivation of agents.

One problem with the argument is that $(2 \mathrm{c})$ does not follow from $(2 \mathrm{a})$ and $(2 \mathrm{~b})$. If $S$ makes a moral judgement and it is mistaken, then $S$ is subject to rational criticism. But from that it does not follow that it is a requirement of reason that $S$ make a moral judgement reflecting the truth of $p$ in the first place. $S$ might make no moral judgement at all.

To drive home this point, it is worth considering the position of John McDowell. He has argued that moral requirements are not requirements of reason. Moral or virtuous agents have a special way of conceiving of the world - for instance the cruelty of a situation - which escapes those lacking in virtue (McDowell 1978: 16). Those lacking in virtue may have some idea of cruelty but they don't see it in its true colours. Only the virtuous will be able to make genuine judgements concerning what they ought to do (e. g. not be cruel). McDowell can allow that, if one makes such a judgement, it is a requirement of reason that one is motivated to act (McDowell 1978: 16). However, he suggests that being virtuous involves something like a perceptual capacity whose lack would not be a failure of rationality (McDowell 1978: 21, 23-24; McDowell 1979: 332).

McDowell can agree with Smith that, if two agents, $\mathrm{S}$ and $\mathrm{T}$, differ in their moral judgements, at least one would be susceptible to rational criticism. However, this is only because both have the perceptual capacity needed for making moral judgements in the first place. If one lacked it, he or she would be unable to make any moral judgements and not subject to rational criticism for failing to do so. It is no failure of rationality to be unable to detect that which one has no means or interest in detecting. There is no requirement of reason to stock up one's mind with all the truths under the sun (see McDowell 1995: 107-110).

Is McDowell able to account for our legitimate expectations concerning agents? I don't think he is in any worse position than Smith. According to Smith, the basis of our legitimate expectation that agents act morally is that moral requirements are requirements of reason for all agents from which they depart on pain of irrationality. According to McDowell, the basis is the virtuous's ability to perceive sui generis moral requirements which escape unvirtuous agents. Each identifies certain conditions in which agents will act in accordance with what is right and writes off those 
occasions in which agents do not as the failure to meet certain standards: of rationality or virtue respectively.

There is one difference between their positions which might suggest an objection to McDowell's view. By holding that moral requirements are requirements of reason for all agents, Smith has explained how we have legitimate expectations about the behaviour of all agents. Moral requirements have been linked to the very idea of agency. By contrast, McDowell cannot say that moral requirements are requirements of reason for all agents, only those with the requisite perceptual capacity. So he cannot explain our legitimate expectations concerning the unvirtuous.

It is questionable whether we do have legitimate expectations about the behaviour of all agents. But let me not press this point in favour of another. Smith's position is only distinct from McDowell's if the rationality involved in agency is indivisible. Smith has given us no reason to think that it is. McDowell distinguishes between rational and virtuous agents. Smith takes rational agency to involve morality. Let a thinly rational agent be one who is not sensitive to moral reasons. Smith's position seems to be that such agents are not possible. But why? Whatever argument Smith provides at this point is likely to be open to McDowell. It is just that he will use it to defend the claim that agency does not just involve rationality but also virtue. As a result, Smith has failed to rule out the possibility that the basis for our legitimate expectations is grounded in the fact that agents are moral.

The second problem with Smith's argument concerns premiss $(2 \mathrm{~d})$, what he calls the Practicality Requirement.

If $S$ judges that it is right for him or her to $\phi$ in $C$ and $S$ is practically rational, then $S$ is motivated to do $\phi$ in $C$ (Smith 1994: 61).

Those who reject it, Externalists, hold that $\mathrm{S}$ needs an independent desire to $\phi$ in circumstances $C$ in order to have a reason to $\phi$ in circumstances C. The debate over the Practicality Requirement is familiar. The question of what grounds our legitimate expectation that agents act as they ought does not provide us with any further leverage. Externalists will say that what grounds our legitimate expectations is our recognition of the fact that agents normally have certain fundamental desires as part of their biological heritage or are normally inculcated with certain fundamental desires as part of their social heritage.

Perhaps it will be argued that this position could not explain how it is a conceptual truth that

(1) If agents are morally required to $\phi$ in circumstances $C$ (i.e. if it is right for agents to $\phi$ in circumstances $\mathrm{C}$ ), then we legitimately expect them to $\phi$ in $\mathrm{C}$. 
The position must allow that there may be some (non-human) agents whose biology does not normally bring with it certain fundamental desires or whose societies do not normally bring with them certain patterns of inculcation. But if this is right, I think Smith has done little to establish that (1) is a conceptual truth rather than a piece of readily available knowledge about the kind of agents with which we are familiar: human agents. So I do not think that this can be counted a significant objection.

Smith has an argument which may seem to throw into question the viability of this second approach. He alleges that the Externalist is committed to a characterization of the morally good as moral fetishists. In order to explain why their motivation changes given a change in their values, Smith says that the Externalist must attribute a de dicto desire that he or she do the right thing implying that they always have the moral in mind (Smith 1994: 71-76). If I (a morally good person) judge that success at work is of less moral value than friendship, I will only be motivated to abandon my striving for the former and try to cultivate the latter if I desire to do the right thing. According to Smith, to conceive of the morally good as having such desires always present in their minds is to conceive of them as morality obsessed - it is to make them moral fetishists. But, as Hallvard Lillehammer points out, this does not seem to be right (Lillehammer 1997: 193-94). A morally good individual may be one who is disposed to form particular desires appropriate to what he or she (now) values - success or friendship - as a result of biology or society. It may be true that such an individual could be ascribed the de dicto desire to do the right thing but this would be a mere ascription - a logical consequence of the fact that the morally good individual displays a sensitivity to the whole range of valuable features. It is his or her complex disposition to make desirous responses to these features that actually explains the shifts in his or her motivational states (cf. Dancy 1993: 7-14). Perhaps Smith will seek to claim that any such disposition must be a substantial version of the de dicto desire and not a mere ascription. I do not need to argue about this. What I claim is that, if substantial desires can be mere dispositions to change desires in the way indicated, then the notion of desires in play is not substantial enough to justify the charge of moral fetishism. ${ }^{2}$

2 In a more recent discussion in response to a similar objection raised by David Brink and David Copp, Smith has suggested that in order for the desires for particular things to play an appropriate role, the Externalist would have to attribute to the morally good the desire to have desires that are at the appropriate strength for morality. One will care about one's family to the morally required degree ... but not too much. Smith makes a similar charge of perversity. Again this seems to rest on taking the ascription of desire to advert to something more substantial than a plausible Externalism need require (Brink 1997: 27-28; Copp 1997: 50-51; Smith 1997: 11516). 


\section{I32 PAUL NOORDHOF}

\section{Rationality, sagacity and moral reasons}

Although, strictly speaking, Smith takes the legitimacy of our expectations concerning how agents act as the justification for Rationalism, I get the impression from reading Smith's work that Rationalism derives an independent plausibility from his account of moral considerations. He holds that moral considerations are normative reasons and gives the following account of normative reasons:

There is a normative reason for $S$ to do $\phi$ in circumstances $C$ if and only if $\mathrm{S}$ would desire to do $\phi$ in $\mathrm{C}$ if he or she were fully rational (Smith 1994: 151-52).

If there is a moral reason for $\mathrm{S}$ to help his or her friend in difficult circumstances, and $S$ fails to desire to help, $S$ is rationally criticizable. That can make it look as if moral requirements are requirements of reason for all agents.

I propose to accept that moral considerations are normative reasons and, for the sake of argument, that something like Smith's account of normative reasons is correct. However, Smith's characterization of full rationality is problematic. Smith claims that full rationality involves having all relevant true beliefs, no relevant false beliefs and being able to deliberate correctly (Smith 1994: 151-58). We have seen that, if an agent could not form (or indeed had no interest in forming), a belief either way on the subject, it is questionable whether an agent's failure to believe is rationally criticizable. We need to find some way to mark this gap whatever terms we use. So let me define sagacity as full rationality in Smith's sense. We might then characterize full rationality as follows. Full rationality involves having all relevant true beliefs that one could be rationally criticized for failing to have, no relevant false beliefs that one could be rationally criticized for having and being able to deliberate correctly. With this adjustment, I shall try to show that the two positions canvassed above - McDowell's and the Externalist's - are compatible with the idea that moral considerations are normative reasons in the sense specified by Smith and reproduced above.

According to McDowell's position, moral reasons would be reasons for virtuous agents since they would have the appropriate perceptual capacity and make moral judgements by this means. Any failure to arrive at the right moral judgement would be rationally criticizable. On the other hand, those agents who lacked this capacity would not be rationally criticizable. Moral reasons would not hold for them.

This would make normative reasons relative to the type of agent envisaged, an idea which has been rejected by Smith. But the reasons that he 
gives would scarcely apply to this case. First, he argues that, if normative reasons were relative to a type of agent, then they would depend entirely upon his or her desires and hence be quite arbitrary. If putative normative reasons applied arbitrarily, then their basis would be undermined (Smith 1994: 172-73). However, as we have seen, McDowell's position is not one in which normative reasons are relative to an agent having certain desires. Second, Smith claims that, if normative reasons were relative to a type of agent, then in talking about normative reasons with other people, we would not be talking about a common subject matter (Smith 1994: 172). This seems false. It is just that, in the case of morality, the subject matter will be common to all virtuous agents and not all agents.

According to the Externalist, certain inculcated or already present desires constitute the basis of our legitimate expectations that agents act morally. Let us assume that these desires are compatible with an agent being fully rational in the sense I have recently specified. It is not a straightforward implication of Externalism that agents may have had other desires than those which are the basis of our legitimate expectations but it is hard to rule out. That suggests that there are many possible sets of desires which are compatible with an agent being fully rational. The normative reasons for $\mathrm{S}$ would be relative to the set of desires, D, S would have if, S became fully rational. Obviously, the membership of $\mathrm{D}$ would be partly determined by the desires $S$ had before becoming fully rational (call them 'the initial desires').

Such a position seems more open to Smith's charges that arbitrariness and absence of a common subject matter would undermine the normativity of the so-called normative reasons. Nevertheless, the second charge certainly will not stick. Once more, contrary to what Smith implies, there will be a common subject matter. It will be grounded in a common entrenched set of fundamental desires deriving from a common biological or social history. It is slightly harder to deal with the charge of arbitrariness. After all, it is quite true that there might have been other desires which were entrenched so generating a different set of normative reasons. The Externalist should just remark that, in fact, normative reasons are hypothetical imperatives. There is nothing arbitrary about what these recommend given the agents' initial desires and the workings of full rationality upon them. So even if normative reasons fail to have categorical force, they do not lack normativity. We just mistakenly suppose the force to be categorical because, first, many of the initial desires are so common and well entrenched that we barely think about their existence and, second, normative reasons apply to us although they do not correspond to desires we currently have but rather to desires we would have if we were fully rational (cf. Smith 1994: 174-75). 
An obvious consequence of my adjustment to Smith's account of full rationality is that at least some normative reasons are not unconditional requirements of reason. They are just requirements of reason given that the agent has certain features. ${ }^{3}$ It might be questioned whether these should count as reasons at all. I think that what makes them legitimately called reasons rather than something else is that they are linked to an agent's motivation in the ways sketched and their link with motivation is justificatory. They illuminate why it would be appropriate to act in the way they recommend, should the agent appreciate them or, in the case of Externalism, have the appropriate initial desires. If this is not enough to make them reasons, then call them something else but it seems to me a perfectly acceptable usage.

\section{Can rationality ground the legitimacy of our expectations?}

The distinction between sagacity and my revised notion of full rationality made in the previous section invites a corresponding distinction between two doctrines concerning the nature of moral reasons: Rationalism and what we might better call Sagism. Sagism can be defined as follows

3 Smith obscures this issue a little. He writes

Suppose, for example, that you and I differ in our preferences for wine over beer. Preferring wine, as you do, you may tell me that there is reason to go to the local wine bar after work for they sell very good wine. But then, preferring beer, as I do, I may quite rightly reply 'That may be a reason for you to go to the wine bar, but it is not a reason for me' .... Now while this may look like the claim that our reasons are relative to our desires .... it isn't really. For the crucial point in this case is that a relevant feature of your circumstances is your preference for wine, whereas a relevant feature of my circumstances is my preference for beer (Smith 1994: 170-71).

He then goes on

as we have seen, because our concept of a normative reason is non-relative, in assessing the truth of such claims we presuppose that fully rational agents would all have the same desires about [what] is to be done and desired in various circumstances. On this account, normative reason claims are therefore categorical imperatives, for agents who face the same circumstances all have the same reasons (Smith 1994: 174-75).

If you include the desires and preferences of the agent as part of the circumstances, then it follows automatically that normative reasons are categorical imperatives whatever one's position. But that just shows that you should not take the desires and preferences of agents as part of the circumstances. The crucial distinction is between those reasons that one would have anyway and those reasons which one would only have if one had certain desires and preferences. This distinction is obscured by Smith's liberal notion of what counts as the circumstances. 
There is a moral reason to do $\phi$ in $\mathrm{C}$ iff ' $\mathrm{Do} \phi$ in $\mathrm{C}$ ' is an unconditional requirement of reason for Sages.

A Sage is someone who has the capacity to know all the relevant truths or falsehoods, is interested in so doing, and is capable of deliberating correctly. The characterization of Sagism captures McDowell's idea that there are moral reasons which non-moral agents may fail to appreciate without irrationality but which are still reasons for all that because they are linked to a certain cognitive ideal: sagacity.

According to Smith, Rationalism was the idea that

If it is right for agents to $\phi$ in circumstances $\mathrm{C}$, then there is a reason for those agents to $\phi$ in $C$ (Smith 1994: 62).

But, if what I have said about normative reasons is correct, then this is too weak. There may be a reason for an agent to $\phi$ in $\mathrm{C}$ without the reason being an unconditional requirement of rationality. So Rationalism should be understood as follows.

There is a moral reason to do $\phi$ in C iff 'Do $\phi$ in C' is a requirement of reason for any rational being.

Smith does not distinguish between Rationalism and Sagism because he takes all agents (i.e. all rational beings) to be Sages. Smith defends the legitimacy of our moral expectations of agents by taking their failure to live up to what is morally required as a departure from sagacity. In normal circumstances, agents will be sagacious and hence it is legitimate to expect that they will act morally. Put like that, it seems incredibly unlikely that our legitimate expectations are so based. There are many things we are incapable of knowing, even if moral requirements don't figure among them. So a general expectation of sagacity can't be the basis of our legitimate expectations. It is a rather revisionary notion of agency to suggest it involves the capacity for sagacity rather than just the capacity for full rationality.

I think Smith then faces something of a dilemma. If he refuses to go into details about the precise nature of moral reasons and just appeals to the legitimacy of our expectations, then he leaves himself open to those who would wish to base the legitimacy of these expectations partly on nonrational grounds, for instance: possession of a moral perceptual capacity or a common entrenched set of desires. Our expectations would be legitimate because we expect the agents we come across to be moral not sagacious. Smith can reject this line by adopting a thinner notion of agency and showing that moral reasons are highly general reasons that characterize the nature of practical rationality in whatever form it takes. There have been attempts to establish this in the Kantian tradition (e. g. see Nagel 
1970). But then it is here that all the argumentative work must be done. The argument from legitimate expectations has no bite. So if we wish to establish the truth of Rationalism, we will not succeed by considering what is the basis of our legitimate expectations of agents. ${ }^{4}$

\author{
University of Nottingham, \\ Nottingham NG7 2RD, UK \\ Paul.Noordhof@nottingham.ac.uk
}

\title{
References
}

Brink, D. O. 1997. Moral motivation. Ethics 108: 4-32.

Copp, D. 1997. Belief, reason, and motivation: Michael Smith's The Moral Problem. Ethics 108; 33-54.

Dancy, J. 1993. Moral Reasons. Oxford: Basil Blackwell.

Lillehammer, H. 1997. Smith on moral fetishism. Analysis, 57: 187-95.

McDowell, J. 1978. Are Moral requirements hypothetical imperatives? Proceedings of the Aristotelian Society, Supplementary Volume, 52: 13-29.

McDowell, J. 1979. Virtue and reason. The Monist 62: 331-50.

McDowell, J. 1995. Might there be external reasons? In World, Mind, and Ethics: Essays on the Ethical Philosophy of Bernard Williams eds. J. E. J. Altham and Ross Harrison. Cambridge: Cambridge University Press. And in his Mind, Value, and Reality (1998). Cambridge, Massachusetts: Harvard University Press: 95-111 (page references in text to latter).

Nagel, T. 1970. The Possibility of Altruism. Princeton, New Jersey: Princeton University Press.

Smith, M. 1994. The Moral Problem. Oxford: Basil Blackwell.

Smith, M. 1997. In defense of The Moral Problem: a reply to Brink, Copp, and SayreMcCord. Ethics 108: 84-119.

${ }^{4}$ My thanks to Michael Clark for saving me from some serious errors, Peter Smith and an anonymous referee from making me express my ideas more clearly. 